\title{
Gerenciamento de resíduos recicláveis do Tribunal de Justiça de Pernambuco: proposição de capacitação dos servidores
}

\section{Eduardo Lemos de Moura1, Luiz Filipe Alves Cordeiro' ${ }^{2}$, , Wanderson dos Santos Sousa ${ }^{2}$, Daniele de Castro Pessoa ${\text { de } \text { Melo }^{2} \text { e Thiago Vasconcelos Modenesi }}^{3}$}

${ }^{1}$ Instituto de Tecnologia de Pernambuco. Mestrado Profissional em Tecnologia Ambiental. Avenida Prof. Luís Freire, 700. Cidade Universitária. Recife-PE, Brasil (CEP 50740-540).

${ }^{2}$ Instituto de Tecnologia de Pernambuco. Av. Prof. Luís Freire, 700. Cidade Universitária. Recife-PE, Brasil (CEP 50740-540). *E-mail: filipecordeiro@gmail.com.

${ }^{3}$ Centro Universitário dos Guararapes. Rua Comendador José Didier 27. Piedade. Jaboatão dos Guararapes-PE, Brasil (CEP 54400-160).

Resumo. As instituições públicas, com sua representatividade e indutoras de comportamento social, devem contribuir com exemplos de práticas saudáveis de gestão ambiental, minimizando os impactos negativos provenientes de suas atividades. 0 presente trabalho tem por objetivo realizar o estudo da percepção ambiental do corpo funcional do Tribunal de Justiça de Pernambuco (TJPE) visando à construção de proposições para o aprimoramento da capacitação com o intuito de elevar a sensibilização desses quanto às questões socioambientais implantadas no gerenciamento de resíduos recicláveis. 0 trabalho foi realizado através de pesquisa bibliográfica, documental e aplicação de questionários direcionados a 167 servidores. Constatou-se como resultados principais que, apesar da gestão sustentável ter obtido resultados positivos, destacou-se o desafio da quebra do paradigma da dicotomia teoria/prática, onde apesar do corpo funcional possuir conhecimentos ambientais, dificuldades foram encontradas, que demandam gestão para aperfeiçoamento na infraestrutura de gerenciamento de resíduos recicláveis e na sensibilização e capacitação dos servidores, visando a uma participação mais efetiva. Diante do exposto, é recomendado rever a infraestrutura implantada, a construção das capacitações, realizando uma educação ambiental contínua, acessível a todos e voltada para despertar o interesse nas práticas saudáveis nas instituições e fomentar o alcance da responsabilidade socioambiental.

Palavras-chave: Educação ambiental; Percepção ambiental; Práticas sustentáveis; Responsabilidade socioambiental.
Recebido

$12 / 11 / 2020$

Aceito

20/12/2020

Disponível on line

$23 / 12 / 2020$

Publicado

$31 / 12 / 2020$

Acesso aberto

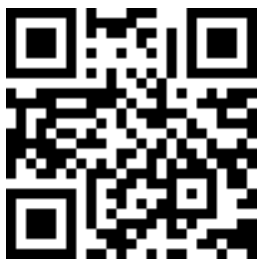

D 0000-0003-3162-6252

Eduardo Lemos de

Moura

ISSN 2359-1412/RBGAS-2020-0166/2020/7/17/38/1637

Rev. Bras. Gest. Amb. Sustent.

http://revista.ecogestaobrasil.net 
Abstract. Management of recyclable waste from the Pernambuco Court of Justice: A proposal for training civil employees. Government institutions, which influence social behavior, must set examples of healthy environmental management practices, contributing to minimizing the negative impacts derived from their activities. Thus, this study aimed to assess the environmental perception of the court staff in Pernambuco (TJPE), aiming at the development of proposals for employee training, improving their awareness of socioenvironmental issues regarding recyclable waste management. To this end, bibliographic documentary research was carried out and questionnaires were applied to 167 employees. As a main result, it was found that, despite the positive results from sustainable management, there was a challenge of applying the theory into practice. Although the court staff has environmental knowledge, some problems were found, which demand measures for improving the infrastructure of recyclable waste management and raising employees awareness, as well as training them for their effective participation. Given the above, it is recommended to review the implemented infrastructure and improve the training program to carry out continuing environmental education accessible to everyone. This will arouse interest in healthy practices in institutions and promote social environmental responsibility.

Keywords: Environmental education; Environmental perception; Sustainable practices; Social and responsibility.
(D) $0000-0001-8146-9465$

Luiz Filipe Alves

Cordeiro

D 0000-0002-2081-3434

Wanderson dos Santos

Sousa

D) 0000-0003-4058-092X

Daniele de Castro

Pessoa de Melo

(D) 0000-0002-8628-0300

Thiago Vasconcelos

Modenesi

\section{Introdução}

Nas últimas décadas, o confronto dos atuais desafios socioambientais em decorrência da crescente degradação à natureza, ganhou cada vez mais visibilidade, tanto no Brasil como no mundo, existindo a necessidade de ações essenciais por parte de toda a sociedade, para a conquista da sustentabilidade ambiental (Carvalho e Estender, 2017), em decorrência dos desafios ambientais globais estarem se manifestando em escala planetária na forma de mudanças climáticas, acidificação dos oceanos, perda de biodiversidade, poluição ambiental, desmatamento e mudança no uso da terra, entre muitos outros (Shrivastava et al., 2020).

Em consequência do exposto, foi constatado um grande avanço das políticas ambientais do país ao longo das últimas cinco décadas, adequando-se as exigências mundiais estabelecidas em conferências de países integrantes da Organização das Nações Unidas (ONU) (Silva et al., 2019). 0 meio ambiente transformou-se em um tema de notória relevância para o governo brasileiro durante esse período, sendo refletido na elaboração de leis e diretrizes sobre questões ambientais, com o intuito de proteção e conservação do ecossistema, contribuindo para a redução de ações danosas e devastadoras para o mesmo, envolvendo tanto as pessoas físicas quanto as jurídicas, no âmbito do direito público e privado. Tal debate acabou dando origem a Lei $\mathrm{n}$ - 12.305/2010, que instituiu a Política Nacional de Resíduos Sólidos (PNRS), dispondo sobre as diretrizes relativas à gestão integrada e ao gerenciamento de resíduos sólidos, e tem como instrumentos, entre outros, a coleta seletiva e a logística reversa (Brasil, 2010). 
O Poder Judiciário Brasileiro se engajou nesta através da Resolução CNJ no 201/2015 (CNJ, 2015), do Conselho Nacional de Justiça, que determinou a adoção de políticas públicas de sustentabilidade e implantação do Plano de Logística Sustentável do Poder Judiciário (PLS-PJ), de caráter obrigatório para todos os tribunais do país. $\mathrm{Na}$ estrutura judiciária existem inúmeras varas e tribunais, com força de trabalho único e de nível elevado, com um quadro constituído por magistrados, servidores, colaboradores e estagiários, produzindo um potencial de resíduos. Diante dessas circunstâncias, existe a necessidade da reflexão do impacto ecossistêmico proveniente da maneira como as atividades dos órgãos judiciários são realizadas e a cultura de sustentabilidade fomentada aos servidores (Guaragni et al., 2019).

Nesse processo, o desenvolvimento de uma consciência cidadã da responsabilidade socioambiental nos gestores e servidores públicos tem sido um grande empecilho para a implantação da Agenda Ambiental na Administração Pública (A3P), e no mesmo momento, imprescindível para o seu êxito (Brasil, 2009). Diante dessas considerações, buscamos aqui responder à questão de pesquisa desse artigo: Quais as dificuldades a serem supridas pelas ações de capacitações para o alcance da efetividade e responsabilidade socioambiental dos servidores na instituição?

É nesse contexto que o presente trabalho é inserido com o objetivo de realizar um estudo da percepção ambiental dos servidores do Tribunal de Justiça de Pernambuco (TJPE) quanto à questão do gerenciamento dos resíduos sólidos recicláveis, buscando o desenho de proposições para o aprimoramento da capacitação visando à elevação da sensibilização desses quanto às questões socioambientais.

\section{Fundamentação teórica}

0 presente tópico aborda os principais conceitos relevantes à pesquisa e alinhados a legislação pertinente e as políticas públicas vigentes, sendo dispostos de maneira a enriquecer o debate sobre o gerenciamento de resíduos recicláveis no Poder Judiciário e demais instituições públicas.

\section{Gerenciamento de Resíduos Sólidos Recicláveis}

Para a PNRS, o gerenciamento de resíduos sólidos diz respeito às ações executadas em conformidade com o plano municipal de gestão integrada de resíduos sólidos ou com o plano de gerenciamento de resíduos sólidos, exigidos na forma da Lei. Englobam, de maneira direta ou indireta, as fases de coleta, transporte, transbordo, tratamento e destinação final ambientalmente adequada dos resíduos sólidos e disposição final ambientalmente adequada dos rejeitos. Devendo ser observada a seguinte ordem de prioridade: não geração, redução, reutilização, reciclagem, tratamento dos resíduos sólidos e disposição final ambientalmente adequada dos rejeitos (Costa e Dias, 2020).

Nesse contexto, Kharat et al. (2019) afirma que o descarte indiscriminado de itens, problemas de poluição e resíduos não tratados, aumentam a contaminação ecológica, criam pressões ambientais e até causam desastres naturais. A resposta inadequada e as consequências da degradação ambiental permanecem como barreiras, particularmente no desenvolvimento da sustentabilidade (Mohammadi et al., 2019), sendo necessário para o alcance da sustentabilidade nas sociedades modernas, que os sistemas de gerenciamento de resíduos sólidos consolidem a reciclagem de resíduos sólidos urbanos (RSU) solidificando os mercados e as indústrias de reciclagem (Expósito e Velasco, 2018).

Nesse sentido, a reciclagem no Brasil tem evoluído, obtendo cada vez mais foco com o passar dos anos, justamente pela necessidade do desenvolvimento de três pilares da vida em sociedade: o econômico, o ambiental e o social. 0 econômico, porque a transformação de resíduos recicláveis pode gerar um aumento de escala no âmbito industrial e comercial; o ambiental, em face de, quanto mais, resíduos forem reciclados, 
menor a quantidade de materiais destinados aos aterros sanitários; e o social, devido que, atualmente os catadores são profissionais reconhecidos, contribuindo com os sistemas de coleta seletiva (Wanderley e Araújo, 2018).

Entre os vários aspectos positivos da reciclagem destacam-se a preservação de recursos naturais, economia de energia, geração de trabalho e renda, e conscientização da população para as questões ambientais (Pimentel et al., 2020), sendo imprescindível para esse processo a segregação adequada dos resíduos com base no seu conteúdo (a saber, orgânicos, plásticos, vidro, metal e combustíveis), e de muita importância para o gerenciamento sustentável dos resíduos, embora não seja amplamente realizado. Essas deficiências só podem ser tratadas com a introdução de pessoal treinado no setor de resíduos e a disseminação da conscientização social (Das et al., 2019).

No sentido de impulsionar essa sistemática a Resolução CONAMA no 275/2001 (Brasil, 2001), estabelece o código de cores para os diferentes tipos de resíduos, a ser adotado na identificação de coletores e transportadores, bem como nas campanhas informativas para a coleta seletiva, devendo seguir essas orientações todos os programas de coleta seletiva, criados e mantidos no âmbito de órgãos da administração pública federal, estadual e municipal, direta e indireta, e entidades paraestatais, conforme o seguinte padrão de cores: azul (papel/papelão), vermelho (plástico), verde (vidro), amarelo (metal), preto (madeira), laranja (resíduos perigosos), branco (resíduos ambulatoriais e de serviços de saúde), roxo (resíduos radioativos), marrom (resíduos orgânicos) e cinza (resíduo geral não reciclável ou misturado, ou contaminado não passível de separação).

Diante dessa contribuição, pode-se afirmar que a coleta seletiva sendo subsidiada desta forma pode gerar alguns benefícios à qualidade ambiental, como a diminuição de emissão de gás carbônico, por conta da redução do número de rotas da coleta de resíduos sólidos; aumento do ciclo de vida útil do material reciclável e redução no impacto ambiental provocado pelos materiais recicláveis na natureza, destinados ao atual aterro sanitário (Sanjad et al., 2019).

Levando-se em consideração o exposto através dos autores, e a grande responsabilidade das instituições públicas e privadas, em especial, o Poder Judiciário de Pernambuco, como entidade de representação política, social e potencial gerador de resíduos, não se excluindo da autoria de fomentar a degradação ambiental através de suas atividades, e usufruindo de sua representatividade, necessita inserir a adoção de práticas saudáveis nas atividades de sua rotina jurídico-administrativa através da capacitação socioambiental, visando a elevar a sensibilização dos envolvidos no processo para o alcance de uma atuação mais efetiva na conquista da responsabilidade socioambiental na instituição.

\section{Capacitação Socioambiental e Sensibilização dos Servidores}

O envolvimento do Estado é essencial, através de ações da sociedade civil organizada e de suas entidades representativas, para que ocorram mudanças efetivas nos hábitos dos cidadãos e se consolidem em atitudes práticas. Foi visando à disseminação de práticas sustentáveis nas instituições públicas, que o Ministério do Meio Ambiente deu origem em 1999, a A3P, e que em 2001, foi transformada em programa de governo, fomentando a criação de uma cultura institucional com foco na produção sustentável e no consumo responsável (Carvalho et al., 2020).

A A3P foi estruturada em seis eixos temáticos prioritários constituídos por ações que visam à redução dos impactos socioambientais negativos (Figura 1). 

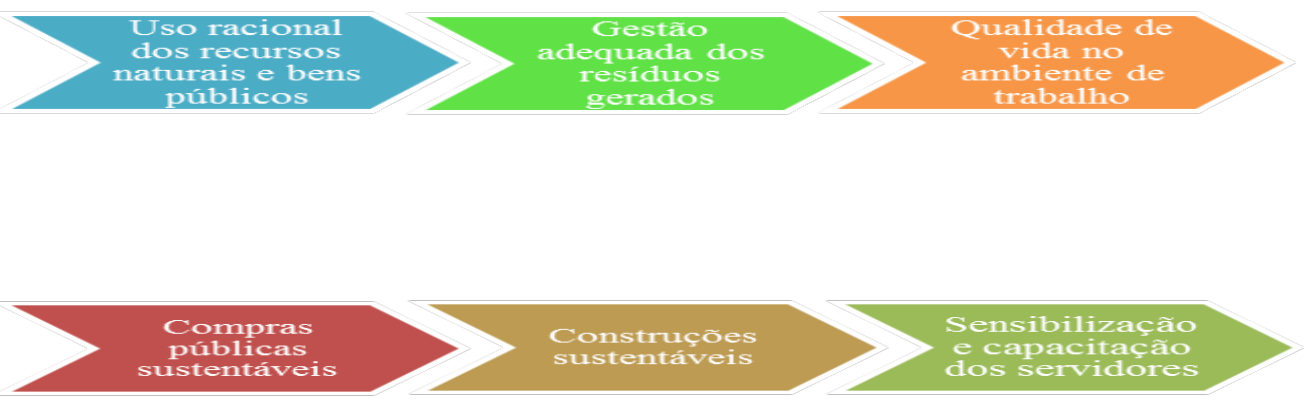

Figura 1. Eixos temáticos da A3P. Fonte: MMA (2009).

Sendo essencial conscientizar o ser humano da sua integração e dependência com a natureza com a finalidade de desenvolver a compreensão do princípio da sustentabilidade, ou seja, viver sem comprometer a vida da geração atual, assim como das futuras, é a função principal da Educação Ambiental; que seguindo esse princípio, propaga os conhecimentos básicos sobre o gerenciamento adequado dos resíduos sólidos que são gerados no nosso cotidiano, tornando-se fundamental para que a sociedade tenha referências para iniciar as transformações necessárias e possa colaborar efetivamente nesse processo (Mello e Lemos, 2019).

A educação ambiental é um tema de bastante relevância na PNRS, pois, em decorrência do princípio da responsabilidade compartilhada, todos os cidadãos possuem deveres e obrigações com os resíduos gerados, devendo elevar a consciência e entender que, melhor do que tratar é não gerar, pois, consequentemente, irá contribuir para a redução na produção de resíduos ou rejeitos, e na quantidade de matéria prima utilizada, não deteriorando de forma desordenada os recursos naturais (Silva et al., 2017).

Como peça essencial, a conscientização e a participação das pessoas estão diretamente associadas ao processo de gerenciamento de resíduos sólidos; os fatores culturais e sociais que caracterizam as atividades das pessoas se transformam em entraves que se refletem na ausência de participações, deficiente cooperação e atitudes negativas dos servidores (Yukalang et al., 2017), portanto, o direcionamento dos servidores sobre sua função na gestão de resíduos, através da conscientização e da comunicação eficaz e regular, é fundamental para incentivar e impulsionar o corpo funcional. Sendo peça integrante dessa campanha, as informações devem ser difundidas através de canais apropriados para desfazer os mitos relacionados à realização de práticas de gerenciamento de resíduos e direcionar para exequíveis mecanismos de correção para seus problemas (Kala et al., 2020).

Diante deste contexto, educar os cidadãos a produzir menos resíduos, além de instalar equipamentos de reciclagem internos que reduzam a carga total de resíduos, torna-se a maneira mais significativa de redução de resíduos (Loan et al., 2019).

\section{Políticas Públicas e Legislação Aplicada em Sustentabilidade}

Foi através do relatório inovador, Nosso Futuro Comum, elaborado na CMMAD organizado pelas Nações Unidas em Estocolmo na Suécia, em 1987, que o termo desenvolvimento sustentável se tornou público, trazendo o conceito de que o desenvolvimento é sustentável quando supre as necessidades atuais sem comprometer a habilidade das futuras gerações de atender suas próprias necessidades. E foi a partir da 
década de 1990, impulsionada pelas recomendações da Comissão, que surgiram os acordos internacionais como a Agenda 21, originada na Conferência das Nações Unidas sobre o Meio Ambiente e Desenvolvimento (CNUMAD), realizada no Rio de Janeiro, em 1992, conhecida como Cúpula da Terra e também como, Rio 92 (Feil e Schreiber, 2017).

Dividida por quatro seções, a Agenda 21 tem por afinidade ao objeto deste trabalho, a seção II - Conservação e Gestão dos Recursos para o Desenvolvimento, capítulo 21, onde destaca o manejo ambientalmente saudável dos resíduos sólidos. Esta Agenda enfatiza a necessidade de estruturar uma ação hierarquizada de objetivos centrada em quatro principais áreas de programas relacionadas aos resíduos, quais sejam: (a) Redução ao mínimo dos resíduos; (b) Aumento ao máximo da reutilização e reciclagem ambientalmente saudáveis dos resíduos; (c) Promoção do depósito e tratamento ambientalmente saudável dos resíduos; (d) Ampliação do alcance dos serviços que se ocupam dos resíduos (Batista et al., 2019).

Seguindo essa tendência global, a Constituição Federal de 1988 (Brasil, 1988) coopera em seu art. 225, determinando que todos tenham direito a um meio ambiente ecologicamente equilibrado, e ao uso comum e essencial para a qualidade de vida sadia, cabendo ao Poder Público e à sociedade o dever de proteger e assegurar esses direitos (Brito et al., 2020).

E foi a partir daí, com o início da década de 1990, que o volume de legislações ambientais impulsionou o desenvolvimento sustentável, assim como os acordos internacionais, que além de estruturar um perfil nas alterações ambientais, incentivaram uma mudança na política global (Costa e Rezende, 2020).

No Brasil, com a criação da Lei no 12.305/2010 (Brasil, 2010), o governo foi em busca de soluções e ações de inúmeros aspectos, principalmente no âmbito ambiental e social, determinando aos municípios à criação de associações de catadores que facilitaria a problemática dos resíduos sólidos de uma maneira ambientalmente adequada e com cunho social inclusivo (Vansetto e Ghisi, 2019).

Enfatizando o dever do Estado, que é de adequar o desenvolvimento sustentável à sua estrutura organizacional, às ações e às políticas públicas, sobretudo estabelecendo práticas equilibradas, determinadas pela Constituição Federal, legislação extravagante, além de tratados e reuniões com representantes internacionais (Guaragni et al., 2019).

0 Poder Judiciário vem também se engajando nessa tendência de medidas protetivas ao meio ambiente, que não é apenas estadual, regional ou nacional, é mundial; e como potencial gerador de resíduos e grande consumidor dos bens finitos do meio ambiente vem através das determinações do CNJ, adotando ações para diminuir os impactos negativos derivados de suas atividades (Oliveira, 2020).

\section{Metodologia}

A pesquisa foi desenvolvida por uma abordagem bibliográfica, documental, de natureza qualiquantitativa e exploratória a partir da análise do gerenciamento de resíduos recicláveis do Centro Integrado da Criança e do Adolescente (CICA), e através de informações da legislação vigente pertinente aos resíduos recicláveis. A escolha da unidade de análise deu-se devido a potencialidade de replicabilidade em outros órgãos e instituições públicas, gerando ecomultiplicadores de práticas sustentáveis.

A coleta de dados desse trabalho abrange o período de 2018 a 2020, sendo realizada por três procedimentos, quais sejam, pesquisa documental (fontes primárias), pesquisa bibliográfica (fontes secundárias) e aplicação de questionários, com a finalidade de captar a percepção dos servidores relativa às questões ambientais. 0 emprego de questionário foi idealizado através da revisão de literatura, retirado e adaptado dos modelos de Brito et al. (2020) e Carvalho et al. (2020), estruturado em um roteiro organizado de questões fechadas, de múltiplas escolhas ou dicotômicas, divididas em cinco 
áreas principais: perfil socioeconômico, conhecimentos quanto às questões ambientais, práticas socioambientais adotadas no cotidiano, estrutura para o gerenciamento de resíduos recicláveis e capacitação socioambiental e sensibilização, aplicadas junto aos servidores do CICA.

A amostra definida para este estudo é probabilística aleatória finita, considerando um nível de confiança de 95\%, erro amostral de 5\%, e tendo por base uma população de 200 servidores. De acordo com a fórmula de cálculo amostral para populações finitas, obteve-se uma amostra mínima de 132 servidores, no entanto, para este trabalho alcançamos as respostas de 167 servidores, sendo este um número aceitável e superior em relação ao nível de confiança estabelecido.

A análise dos dados ocorreu a partir de sua triangulação, pautada pelo referencial teórico utilizado e pelo objetivo proposto. Diante disso, os elementos fundamentais de análise se voltaram, inicialmente na estrutura do gerenciamento de resíduos recicláveis implantada pelo TJPE, realizando uma comparação entre o que foi implantado e seus resultados, e a percepção dos servidores, traçando a problemática através das deficiências encontradas e buscando a solução ou o aperfeiçoamento com as experiências retratadas na literatura pertinente ao tema.

Por conseguinte, foram utilizadas diversas fontes de evidências, consoantes já descritas nessa seção, complementares e distintas, permitindo linhas convergentes de investigação e a triangulação dos dados (Machado et al., 2019).

\section{Resultados e discussão}

A análise foi realizada nos resultados obtidos através de consulta ao Relatório de Desempenho Anual PLS-TJPE (2018/2019) (Pernambuco, 2019), onde teve retratado o panorama institucional, e por meio da pesquisa de percepção dos servidores, mediante a aplicação de questionários.

O Relatório de Desempenho apresenta a performance da instituição quanto as práticas socioambientais implantadas, os indicadores sugeridos, as metas cumpridas e os resultados alcançados. Assim sendo, seguem as metas e resultados referentes ao ano de 2019 (Tabela 1).

Tabela 1. Metas estipuladas e resultados obtidos PLS-TJPE (2018/2019).

\begin{tabular}{|c|c|c|}
\hline Relatório de Desempenho Anual & Metas & Resultados \\
\hline \multicolumn{3}{|c|}{ Eixo 1 - Uso racional dos recursos naturais e bens públicos } \\
\hline Consumo de papel branco (resma) & 59.256 & 69.187 \\
\hline Consumo de copos descartáveis (50 mL) (cento) & 3.589 & 3.687 \\
\hline \multicolumn{3}{|c|}{ Eixo 2 - Gestão de resíduos } \\
\hline Destinação ambientalmente correta do papel (kg) & 20.000 & 18.800 \\
\hline Coleta geral (kg) & 1.928 & 7.652 \\
\hline Destinação à reciclagem (kg) & 21.928 & 26.470 \\
\hline \multicolumn{3}{|c|}{ Eixo 3 - Capacitação e sensibilização } \\
\hline Ações de capacitação e sensibilização dos servidores & 8 & 14 \\
\hline Participação de servidores nas ações de capacitação & 475 & 610 \\
\hline
\end{tabular}

Fonte: Adaptado do Relatório de Desempenho do TJPE (Pernambuco, 2019). 
Para o TJPE, o uso racional dos recursos naturais e bens públicos (Eixo 1), tem sido um tema bastante relevante, pois, além da questão ambiental, contribui também com os aspectos econômicos, reduzindo significativamente, os gastos.

Campanhas internas de sensibilização são realizadas, no que diz respeito à utilização de garrafas para água e o uso de canecas em substituição aos copos descartáveis, utilização da função frente e verso na impressora visando à redução no consumo de papel branco, a realização de cursos de capacitação socioambiental relativos ao esclarecimento quanto aos objetivos de desenvolvimento sustentável, as práticas sustentáveis, aos impactos provenientes do uso de papel, de copos descartáveis, dentre outros.

Em conformidade com o propósito inicial da A3P, esse eixo temático compreendia a adoção de medidas para a racionalização de gastos e consumos de papel e copos (50 e $200 \mathrm{~mL}$ ), e que em razão do trâmite eletrônico de documentos, a quantidade e a diversidade de materiais de consumo foram alteradas de forma significativa, requerendo do gestor medidas de adaptabilidade e inovação diante das mudanças apresentadas, segundo Scartezini (2019).

No que diz respeito ao segundo eixo temático, gestão adequada dos resíduos gerados, o TJPE instituiu a Coleta Seletiva Solidária, através de convênio firmado em parceria com as cooperativas de Trabalho de Catadores de Materiais Recicláveis (COOPAGRES) e a Bola na Rede, que se alternam a cada seis meses na coleta de materiais recicláveis das dependências do TJPE contribuindo com a destinação ambientalmente correta dos resíduos gerados, em conformidade com os Objetivos de Desenvolvimento Sustentável (ODS).

Quanto ao terceiro eixo temático, capacitação e sensibilização, o TJPE realiza diversas campanhas de capacitação e ações na busca da sensibilização dos servidores para práticas socioambientais como a realização de palestras sobre o uso racional da água, do papel, a realização de feiras orgânicas, campanhas para arrecadação de esponjas de limpeza, óleo comestível, pilhas para a destinação ambientalmente corretas; além da realização da Semana do Meio Ambiente, na semana em que se comemora o Dia Mundial do Meio Ambiente, através do Projeto ECOS PERNAMBUCO realizada em parceria com a Universidade Federal Rural de Pernambuco, o Tribunal de Contas do Estado de Pernambuco, o Tribunal Regional Federal da 5a Região e o Tribunal Regional do Trabalho da 6a Região, onde são realizadas trilhas ecológicas, passeios ciclísticos, palestras direcionadas a temáticas ambientais, dentre tantas outras.

Mesmo diante de medidas inseridas, pelo TJPE, em seu contexto institucional como o Processo Eletrônico Judicial (PJE), o Sistema Eletrônico de Informações (SEI) e as campanhas de sensibilização e capacitação realizadas não foram suficientes para o cumprimento de algumas metas estipuladas em alguns indicadores no PLS, como o consumo de papel branco, o consumo de copo descartável de $50 \mathrm{ml}$ e a destinação de papel para a reciclagem.

Evidenciando o que afirma Cândido e Almeida (2019), para o alcance de algumas metas, há necessidade do TJPE aprimorar ou reformular as ações indicadas no PLS, para atingir os resultados visados, respeitando sempre o aprimoramento contínuo da maneira como as ações são construídas nos órgãos que o integram sendo imprescindíveis para a implantação de um modelo de gestão socioambiental, ratificando a hipótese de que o plano de gestão carece de maior sensibilização dos atores envolvidos para seu cumprimento da forma efetiva e sustentável.

A pesquisa de percepção foi realizada com o propósito de compreender e mensurar o nível de conscientização dos servidores em relação às questões ambientais com a finalidade de aprimorar as ações de capacitação para o alcance da responsabilidade na instituição. Essa pesquisa foi dividida em cinco áreas temáticas (Tabela 2). 
Tabela 2. Pesquisa de percepção dos servidores.

\begin{tabular}{|c|}
\hline 1. Aspectos Socioeconômicos \\
\hline 1.1 Você é servidor do TJPE há quanto Tempo? \\
\hline 1.2 Qual o seu gênero? \\
\hline 1.3 Qual o último grau concluído? \\
\hline 1.4 Qual o seu vínculo com o TJPE? \\
\hline 2. Conhecimentos dos servidores com relação à questão ambiental? \\
\hline 2.1 Questões ambientais é um tema que possui relevância para você? \\
\hline 2.2 Você sabe o que significa coleta seletiva? \\
\hline 2.3 Pra você é importante a implantação da coleta seletiva no Tribunal? \\
\hline 2.4 Você acha importante a reciclagem para a preservação do meio ambiente? \\
\hline 3. Práticas socioambientais adotadas pelos servidores em seu cotidiano \\
\hline 3.1 Você utiliza copos descartáveis em sua rotina diária de trabalho? \\
\hline 3.2 Você leva sua própria garrafa de água para o trabalho todos os dias? \\
\hline 3.3 Você leva sua própria caneca para tomar café no trabalho todos os dias? \\
\hline 3.4 Você procura sempre que possível utilizar a função frente e verso na hora de imprimir? \\
\hline 3.5 Você já participou ou colaborou com algum projeto de sustentabilidade do Tribunal? \\
\hline 3.6 Na rotina diária, você sempre faz a separação dos resíduos nas dependências do Tribunal? \\
\hline 4. Estrutura para o gerenciamento de resíduos recicláveis \\
\hline 4.1 Existe dificuldade em encontrar coletores seletivos em seu ambiente de trabalho? \\
\hline 4.2 Você considera que o Tribunal te estimula à práticas de ações sustentáveis? \\
\hline 5. Capacitação socioambiental e sensibilização dos servidores \\
\hline $\begin{array}{l}\text { 5.1 Capacitar servidores do Tribunal em assuntos relacionados à sustentabilidade tem importância } \\
\text { para você? }\end{array}$ \\
\hline 5.2 Você já participou de capacitação voltada para sensibilização de práticas sustentáveis? \\
\hline 5.3 Caso não tenha participado de capacitação, qual a dificuldade encontrada? \\
\hline 5.4 Caso já tenha participado de capacitação, em que momento de sua vida ocorreu? \\
\hline $\begin{array}{l}5.5 \text { Em relação à capacitação relativa a práticas sustentáveis que você participou, trouxe mudanças } \\
\text { de hábitos em sua rotina? }\end{array}$ \\
\hline
\end{tabular}

Fonte: Adaptado de Brito et al. (2020) e Carvalho et al. (2020).

Inicialmente, foram investigados alguns aspectos socioeconômicos dos servidores, considerados importantes para essa pesquisa, obtendo-se um perfil dos servidores colaboradores, 44,3\% dos respondentes estão no TJPE há mais de 21 anos, 65,3\% pertencente ao sexo feminino, $60 \%$ possuem pós-graduação e $84,8 \%$ possuem vínculo efetivo com o TJPE. O corpo funcional formado em sua maioria por pessoas concursadas, com mais de 21 anos de serviço, evidencia que o maior desafio no gerenciamento de resíduos recicláveis do TJPE é mudar o comportamento institucional, criando a consciência cidadã da responsabilidade ambiental nos servidores, sendo necessário o rompimento de um paradigma, consolidado culturalmente.

Sendo essencial, por conta da maneira como a sociedade se apodera dos recursos da natureza, conforme Melo et al. (2020), impor aos grupos sociais a procura de novos modos de agir, individual e coletivamente, de novos procedimentos e formas de produzir bens para atender as necessidades humanas.

Quanto aos conhecimentos dos servidores com relação à questão ambiental, 91,5\% concordam serem importantes temas relacionados a questões ambientais, 87,3\% dizem saber o significado de coleta seletiva, $86,7 \%$ concordam ser importante a implantação da coleta seletiva nas dependências do TJPE e $89,7 \%$ ser importante a reciclagem para a preservação do meio ambiente. 
Apesar disso, os resultados referentes à gestão de resíduos retratados no Relatório de Desempenho Anual, em relação à coleta e destinação do papel para a reciclagem, demonstram resultados adversos, ficando 5,91\% abaixo da meta estipulada. Já no que diz respeito à coleta geral que abrange vidros, plásticos e metais, a meta foi cumprida com um desempenho excelente, ultrapassando em $296 \%$ e contribuindo para a elevação do desempenho do indicador destinação à reciclagem, superando a meta em $20 \%$.

Analisando esses resultados podemos afirmar que mesmo com o corpo funcional possuindo um bom nível de conhecimento em relação às questões ambientais e mesmo a gestão colhendo alguns resultados positivos, muito ainda precisa ser aprimorado com relação à efetividade nas ações, constatado no processo de coleta e destinação do papel para a reciclagem, evidenciando necessidade de averiguar as dificuldades encontradas nessa etapa para se buscar soluções e direcionar as capacitações nesse sentido.

No que diz respeito à infraestrutura de gerenciamento dos resíduos recicláveis, apesar da maioria concordar na relevância da implantação de coletores seletivos nas dependências do TJPE e na relevância da reciclagem para o meio ambiente, diante da realidade constatamos que os coletores seletivos das unidades organizacionais do TJPE foram adquiridos mediante doação através de convênio firmado com a Organização Não Governamental (ONG) Moradia e Cidadania em 2009, sendo em sua maioria ainda usual nos dias de hoje, necessitando de renovação e adequação a demanda observada, despertando dessa forma o interesse contínuo dos servidores em contribuir de forma mais efetiva com a segregação prévia dos resíduos recicláveis para a coleta seletiva solidária, visando à destinação ambientalmente adequada dos resíduos recicláveis e fomentando o processo de reciclagem com resíduos de qualidade.

Nesse contexto, de acordo com Dubois et al. (2017), a educação se torna uma ferramenta de amplitude das expectativas relacionadas ao meio ambiente, concorrendo para uma percepção maior, revigorando, dessa forma, a consciência ambiental e fomentando a sustentabilidade para a transformação da realidade organizacional.

As práticas socioambientais adotadas pelos servidores em seu cotidiano são ações fundamentais para todo e qualquer tipo de gerenciamento de resíduos, contribuindo para a obtenção do êxito em sua formalização. De acordo com os resultados da pesquisa, $60 \%$ afirmam utilizarem copos descartáveis em sua rotina de trabalho, 61,8\% levam sua própria garrafa para beber água no dia a dia do trabalho, 54,9\% levam sua própria caneca para tomar café no trabalho diariamente e que 58,2\% se utilizam da função frente e verso na impressora na hora de imprimir. Em sintonia com o que afirma Silva et al. (2020), ser imprescindível que a sociedade adquira práticas sustentáveis em seu cotidiano e que os gestores públicos apliquem os recursos de modo adequado neste sentido.

No entanto, seguindo ainda por esse eixo temático, 69,7\% afirmam nunca terem participado ou colaborado com algum projeto de sustentabilidade implantado pelo TJPE, e que apenas $32,1 \%$ realizam a separação dos resíduos gerados no TJPE. Nesse entendimento, Gazzoni (2018), destacou a necessidade de maior engajamento dos atores envolvidos, sendo imprescindível à implantação de uma política institucional voltada para o desenvolvimento sustentável, e Melo et al. (2020), concluíram que o processo de reciclagem é constituído por várias etapas, porém, a separação prévia dos materiais é uma ação essencial para a sua realização, evitando que os resíduos sejam dispostos de modo convencional, pois assim, misturados, são pouco aproveitados, prejudicando a separação e a qualidade.

Analisando os resultados referentes ao uso racional de recursos naturais e bens públicos, conforme o Relatório anual, o consumo do papel branco não atingiu a meta estipulada no PLS, superando em 16,76\%, quanto ao consumo de copos descartáveis de água $(200 \mathrm{~mL})$, ficou abaixo da meta em 3,07\%, cumprindo a meta estipulada, no entanto, o consumo de copos de café (50 mL) ficou acima da meta em 2,07\%, necessitando de medidas de contenção. 
Utilizando como parâmetro comparativo, pesquisa de percepção e Relatório Anual conclui-se que, mesmo com todas as medidas inseridas no contexto institucional do TJPE como, a implementação do Processo Judicial Eletrônico (PJE), o Sistema Eletrônico de Informações (SEI) e campanhas de comunicação internas direcionadas ao esclarecimento dos impactos causados pelo consumo de papel e plásticos, não foram suficientes para 0 atingimento do proposto na meta planejada para todos os indicadores.

E apesar da maioria concordar com a relevância das questões ambientais e da implantação da coleta seletiva nas dependências do TJPE, e da evolução nas práticas socioambientais adotadas pelos servidores em seu dia a dia, observou-se ainda, uma resistência em participar ou colaborar com projetos de práticas sustentáveis e que uma pequena parte faz efetivamente a separação dos resíduos nas dependências do TJPE, denotando a necessidade de ações de capacitação direcionadas a esclarecer sobre a importância da segregação dos resíduos para a reciclagem e consequentemente, para o gerenciamento de resíduos, e de ações legítimas que obtenham resultados reais para se atingir o êxito no gerenciamento dos resíduos e induzir a práticas sustentáveis de forma permanente no cotidiano, como campanhas incentivadoras realizadas entre setores, premiando de alguma forma, os que tiverem uma maior participação, com o intuito de impulsionar a separação dos resíduos gerados e consequentemente, a destinação ambientalmente adequada.

No que diz respeito, a estrutura para o gerenciamento de resíduos recicláveis do TJPE, 63,2\% concordam que o TJPE não estimula o servidor à prática de ações sustentáveis, enquanto que $63,6 \%$ dizem terem dificuldade em encontrar coletores seletivos em seu ambiente de trabalho, contrariando Yukalang et al. (2017), que afirmam que todo sistema de gerenciamento de resíduos que funcione bem permite que os atores descartem seus resíduos de maneira adequada. Os componentes de um sistema de gerenciamento de resíduos incluem as instalações e equipamentos usados para armazenar temporariamente os resíduos (caixas de coleta) ou transferir os resíduos coletados para o local de descarte final.

Diante desses resultados, podemos dizer que, a maioria dos servidores não se sente estimulada pelo TJPE a praticar ações sustentáveis, havendo a necessidade de reaver os métodos de capacitação buscando estimular os servidores para as práticas sustentáveis não apenas no ambiente de trabalho, mas, incorporando em sua rotina diária, hábitos saudáveis naturalmente praticados. E que o baixo percentual dos servidores $(32,1 \%)$ que fazem a separação dos resíduos nas dependências do TJPE justificam-se possivelmente, pela dificuldade de encontrar coletores seletivos em seu ambiente de trabalho, denotando falha que contribui para que o gerenciamento de resíduos não se torne efetivo e logre êxito, evidenciando ser primordial uma reformulação na infraestrutura delineada, visando aos ajustes para a solução da problemática, identificando os locais de maior demanda e os tipos de resíduos, como também a realização de campanhas de incentivo à contribuição dos servidores na destinação ambientalmente correta dos resíduos gerados.

Kala et al. (2020) salientam que o direcionamento dos servidores sobre sua função na gestão de resíduos, através da conscientização e da comunicação eficaz e regular, é fundamental para incentivar e impulsionar o corpo funcional. Sendo peça integrante dessa campanha, as informações devem ser difundidas através de canais apropriados para desfazer os mitos relacionados à realização de práticas de gerenciamento de resíduos e direcionar para exequíveis mecanismos de correção para seus problemas.

Merece destaque a temática capacitação socioambiental e sensibilização dos servidores, analisando os resultados dessa pesquisa, constatou-se que $86 \%$ concordam com a importância de capacitação dos servidores em assuntos relacionados à sustentabilidade; $71,5 \%$ afirmam nunca terem participado de capacitação voltada para a sensibilização de práticas sustentáveis; desses que nunca participaram de capacitações, $49,6 \%$ justificam a não participação por nenhum curso ter lhe despertado o interesse e

Rev. Bras. Gest. Amb. Sustent., 2020, vol. 7, n. 17, p. 1637-1652. 
$29,6 \%$ afirmam que o horário do curso coincidia com o do expediente de trabalho; 69,3\% dizem que a última capacitação em que participou foi há mais de um ano e 52,1\% que após terem participado da capacitação, seus hábitos diários se modificaram, sendo bastante influenciados.

Podemos afirmar que mesmo a maioria sabendo da importância da capacitação dos servidores com temas relacionados à sustentabilidade, a falta de estímulo por parte do TJPE afirmada pela maioria, temas das capacitações pouco interessantes, coincidência de horários (curso x trabalho), nos levam a concluir que esses entraves contribuem para 0 elevado percentual de servidores $(71,5 \%)$, que nunca participaram de capacitação voltada para sensibilização de práticas sustentáveis.

Diante de tantas dificuldades traçadas pelos servidores em participar das capacitações, é perceptível a necessidade de reformas na gestão de gerenciamento de resíduos, procurando detectar os problemas e direcionar para soluções, sanando proporcionalmente à falta de estimulo, as dificuldades de acesso e dos horários disponíveis, implantando na cultura organizacional uma maior assiduidade na realização das capacitações, adequando à realidade da instituição e dos seus colaboradores, buscando sempre o aprimoramento das ações na busca de despertar o interesse dos servidores em adquirir conhecimentos relativos a práticas sustentáveis e inserir em sua rotina.

Para Abrantes (2017), é necessário, para que o trabalho almejado seja eficiente, que sejam originados espaços de aprendizagem, com abordagens específicas, em que a sustentabilidade esteja inserida, e que a educação e a conscientização tenham a participação de todos os atores envolvidos no processo. Gazzoni (2018) pactua nesse mesmo sentido, alegando que essas ações, referentes ao tema desenvolvimento sustentável, são imprescindíveis, para o crescimento do conhecimento dos servidores no referido campo.

\section{Considerações finais}

Diante da problemática ambiental, ao longo dos anos, apresentar-se em escala crescente, e diante de ações do governo atual provocando o desmonte das políticas ambientais, estabelecendo o retrocesso no que diz respeito ao direcionamento para o futuro planejado pela Agenda 2030, faz-se necessário uma atuação mais efetiva das instituições públicas, privadas e da sociedade em geral na tentativa de reverter essa situação.

Através dessa pesquisa, observou-se que a temática sustentabilidade e meio ambiente no TJPE é fundamental ser inserida em suas atividades laborais, como medidas mitigadoras dos efeitos ambientais negativos decorrentes de suas atividades, e tem obtido resultados positivos, embora ainda existam dificuldades que demandam gestão para aperfeiçoamento.

Para o presente trabalho, buscou-se analisar as deficiências e a percepção dos servidores quanto ao gerenciamento de resíduos recicláveis, implantado com o intuito de delinear as coordenadas para o aprimoramento das capacitações socioambientais visando a elevar a sensibilidade e obter um maior engajamento dos servidores no processo.

Com os resultados obtidos por meio dos dados coletados no Relatório de Desempenho e na Pesquisa de Percepção, observamos que mesmo com todas as medidas socioambientais inseridas pelo TJPE em seu contexto institucional, com os dados do Relatório indicando que foi superada a meta no número de capacitações realizadas e no número de participantes, o elevado nível de conhecimentos nas questões ambientais, o excelente desempenho da coleta geral (plásticos, vidros e metais) destinando adequadamente os resíduos para a reciclagem, ainda assim, contrariando o Relatório, quando consultados os servidores, foram constatados problemas como, deficiências na 
infraestrutura implantada, falta de estímulo dos servidores, ausência da maioria dos servidores na participação em capacitações ou que colaboraram com projetos de sustentabilidade do TJPE, relatos de dificuldades em participar das capacitações, necessitando de reformulações no que diz respeito à infraestrutura implantada tanto no gerenciamento de resíduos quanto nas capacitações ofertadas, nas elaborações das temáticas ambientais das capacitações e na forma de transmitir as informações. Sendo necessárias soluções para os entraves, buscando sempre atrair a atenção e estimular os servidores para uma participação mais ativa, sendo imprescindível na educação ambiental, o aprimoramento e a continuidade, visando a tornar hábitos saudáveis, em hábitos naturais do cotidiano das pessoas, seja em casa ou no ambiente de trabalho, fomentando a responsabilidade socioambiental nas instituições e na sociedade em geral.

Partindo do construto aplicado, foi possível concluir que é justamente a dicotomia teoria/prática que instaura o desafio de articular os propósitos dos ditames legais e o arranjo de potenciais e deficiências identificado no grupo estudado. Como constatado nos resultados da pesquisa, um dos maiores desafios no que diz respeito à efetuação de práticas sustentáveis no âmbito interno das instituições, inclusive as públicas, é não apenas propor ações, mas, dedicar-se à sua manutenção e firmar seus resultados de acordo com o planejado.

Dentre as limitações, tem-se a aplicação dos questionários direcionada apenas aos servidores, não envolvendo todo o corpo funcional, que é composto por magistrados, servidores, colaboradores e estagiários, o que pode restringir à análise a categoria analisada.

Como sugestão, a replicabilidade da metodologia em outras instituições que compõem o Poder Judiciário e demais instituições públicas, analisando a percepção do corpo funcional no que diz respeito a efetiva prática socioambiental e as dificuldades encontradas.

Ressaltando, por fim, que o presente trabalho não teve a pretensão de esgotar um tema tão relevante e atual, ao contrário, a intenção é atingir o escopo de refletir e propagar a responsabilidade socioambiental das instituições no pós-consumo, através da diminuição do desperdício e do uso dos recursos naturais, e da essencialidade da sensibilização dos atores desse processo através das capacitações.

Esperamos que esse trabalho possa contribuir com a administração pública como um todo, disseminando a conscientização de seu papel na construção de uma sociedade com maior qualidade de vida para presente e futuras gerações.

\section{Conflito de interesses}

Os autores declaram não haver conflito de interesses.

\section{Referências}

Abrantes, M. L. M. Análise das práticas de responsabilidade e sustentabilidade da administração pública: um estudo de caso do Prêmio da Qualidade do Governo Federal do Brasil. Revista Eletrônica do Mestrado em Educação Ambiental, v. 34, n. 3, p. 55-71, 2017. https://doi.org/10.14295/remea.v34i3.7113

Batista, A. S.; Moraes, I. C.; Albuquerque, J. L.; Correia Neto, J. S. Gestão ambiental nas universidades públicas federais: a apropriação do conceito de desenvolvimento sustentável a partir da Agenda Ambiental na Administração Pública. Id on Line - Revista Multidisciplinar e de Psicologia, v. 13, n. 44, p. 276-292, 2019. 
Brasil. Lei no 12.305, de 2 de agosto de 2010. Institui a Política Nacional de Resíduos Sólidos; altera a Lei no 9.605, de 12 de fevereiro de 1998; e dá outras providências. Disponível em: <http://www.planalto.gov.br/ccivil_03/_ato2007-2010/2010/lei/ 112305.htm>. Acesso em: 24 mar. 2020.

Brasil. Resolução CONAMA no 275, de 25 de abril de 2001. Estabelece código de cores para diferentes tipos de resíduos na coleta seletiva. Disponível em: <http://www2.mma.gov.br/port/conama/legiabre.cfm?codlegi=273>. Acesso em: 24 mar. 2020.

Brito, L. M.; Machado, V. L.; Oliveira, L. A.; Poquiviqui, A. Práticas ambientais no Poder Judiciário: uma análise da gestão do Fórum na Comarca de Juara - MT. Revista Destaques Acadêmicos, $\quad$ v. 12, n. 1, p. 182-195, 2020. https://doi.org/10.22410/issn.21763070.v12i1a2020.2502

Cândido, M. C.; Almeida, E. G. A responsabilidade socioambiental no âmbito do Tribunal de Justiça do Estado de Goiás. Humanidades \& Tecnologia em Revista (FINOM), v. 19, n. 8, p. 103-117, 2019.

Carvalho, R. L. V.; Albuquerque, J. L.; Quevedo, A. P. F.; Veloso, G. M. B.; Correia Neto, J. S.; Alves, J. L. Sustainable university management practices. Journal of Environmental Analysis and Progress, v. 5, n. 1, p. 169-180, 2020. https://doi.org/10.24221/ jeap.5.2.2020.2990.169-180

Carvalho, V. G.; Estender, A. C. Conscientização ambiental contribuindo para eliminar o desperdício e ampliar as ações a favor do meio ambiente. Revista Desafios, v. 4, n. 2, p. 150-166, 2017.

CNJ - Conselho Nacional de Justiça. Resolução CNJ no 201, de 3 de março de 2015. Dispõe sobre a criação e competências das unidades ou núcleos socioambientais nos órgãos e conselhos do Poder Judiciário e implantação do respectivo Plano de Logística Sustentável (PLS-PJ). Disponível em: <https://atos.cnj.jus.br/atos/detalhar/2126>. Acesso em: 24 mar. 2020.

Costa, I. M.; Dias, M. F. Evolution on the solid urban waste management in Brazil: A portrait of the Northeast Region. Energy Reports, v.6, n. 1, p. 878-884, 2020. https://doi.org/ 10.1016/j.egyr.2019.11.033

Costa, M. X. R.; Rezende, G. B. M. Agenda Ambiental na Administração Pública: adesão do Departamento Estadual de Trânsito de Mato Grosso às diretrizes do programa A3P. Revista Gestão e Sustentabilidade Ambiental, v. 9, n. 2, p. 610-643, 2020.

Das, S.; Lee, S.-H.; Kumar, P.; Kim, K.-H.; Lee, S. S.; Bhattacharya, S. S. Solid waste management: Scope and the challenge of sustainability. Journal of Cleaner Production, v. 228, p. 658-678, 2019. https://doi.org/10.1016/j.jclepro.2019.04.323

Dubois, A. M.; Silvério, A. P.; Tolentino-Neto, L. C. B. Educar para a sustentabilidade: administração pública federal brasileira em foco. Revista Eletrônica do Mestrado em Educação Ambiental, v. 34, n. 3, p. 55-71, 2017.

Expósito, A.; Velasco, F. Municipal solid-waste recycling market and the European 2020 horizon strategy: A regional efficiency analysis in Spain. Journal of Cleaner Production, v. 172, p. 938-948, 2018. https://doi.org/10.1016/j.jclepro.2017.10.221

Feil, A. A.; Schreiber, D. Sustentabilidade e desenvolvimento sustentável: desvendando as sobreposições e alcances de seus significados. Cadernos EBAPE.BR, v. 15, n. 3, 2017. 
Gazzoni, F. O papel das IES no desenvolvimento sustentável: estudo de caso da Universidade Federal de Santa Maria. Revista Gestão Universitária na América Latina GUAL, v. 11, n. 1, p. 48-70, 2018. https://doi.org/10.5007/1983-4535.2018v11n1p48

Guaragni, F. A.; Barros, E. G.; Knoerr, F. G. Poder Judiciário e meio ambiente: uma gestão judiciária sustentável. Revista da Faculdade de Direito da FMP, v. 14, n. 1, p. 76-86, 2019.

Kala, K.; Bolia, N. B.; Sushil, S. Waste management communication policy for effective citizen awareness. Journal of Policy Modeling, v. 42, n. 3, p.661-678, 2020. https://doi.org/10.1016/j.jpolmod.2020.01.012

Kharat, M. G.; Murthy, S.; Kamble, S. J.; Rauth, R. D.; Kamble, S. S.; Kharat, M. G. Fuzzy multicriteria decision analysis for environmentally conscious solid waste treatment and disposal technology selection. Technology in Society, v. 57, p. 20-29, 2019.

Loan, L. T. T.; Takahashi, Y.; Nomura, H.; Yabe, M. Modeling home composting behavior toward sustainable municipal organic waste management at the source in developing countries. Resources, Conservation and Recycling, v. 140, p.65-71, 2019. https://doi.org/10.1016/j.resconrec.2018.08.016

Machado, R. E.; Rafael, D. H.; Cabral, S. M.; Figueiró, P. S. O empreendedorismo social como oportunidade de inclusão social: o caso de uma cooperativa de reciclagem. Revista de Gestão Ambiental e Sustentabilidade, v. 8, n. 1, p. 1-18, 2019.

Mello, M. C.; Lemos, J. L. S. A importância da difusão de práticas ambientais sustentáveis para a gestão dos resíduos sólidos. Revista Episteme Transversalis, v. 10, n. 3, p. 29-47, 2019.

Melo, J. R.; Cintra, L. S.; Luz, C. N. M. Educação ambiental: reciclagem do lixo no contexto escolar. Revista Multidebates, v. 4, n. 2, p. 133-141, 2020.

MMA - Ministério do Meio Ambiente. A3P: Agenda ambiental na administração pública. 5. ed. Brasília: MMA, 2009. Disponível em: <http://www.mma.gov.br/ estruturas/a3p/_arquivos/cartilha_a3p_36.pdf>. Acesso em: 28 maio 2019.

Mohammadi, M.; Jämsä-Jounela, S.-L.; Harjunkoski, I. Optimal planning of municipal solid waste management systems in an integrated supply chain network. Computers \& Chemical Engineering, v. 123, p.155-169, 2019. https://doi.org/10.1016/ j.compchemeng.2018.12.022

Oliveira, K. M. M. Cumprimento da Resolução no 201/2015 do Conselho Nacional de Justiça e a destinação de resíduos sólidos do Tribunal de Justiça do Estado de Roraima. Revista Ambiente: Gestão e Desenvolvimento, v. 13, n. 1, p. 129-141, 2020.

Pernambuco. Relatório de desempenho 2019. Recife: TJPE, 2019. Disponível em: <http://www.tjpe.jus.br/web/planejamento/pls-2018/2019/relatorios>. Acesso em: 01 ago. 2020.

Pimentel, C. H. L.; Nóbrega, C. C.; Jucá, J. F. T.; Pimentel, U. H. O.; Martins, W. A. A gestão das rotas tecnológicas de tratamento e destinação final dos resíduos sólidos urbanos no Município de João Pessoa/PB. Brazilian Journal of Development, v. 6, n. 2, p. 7063-7088, 2020. https://doi.org/10.34117/bjdv6n2-126

Sanjad, H. C.; Araújo Jr., A. J. S.; Costa, C. E. A. S. Reciclagem como alternativa para reduzir despesas gerenciais no setor de resíduos. Revista Observatorio de la Economia Latinoamericana, Dec, p 1-15, 2019. Disponível em: <https://www.eumed.net/rev/ oel/2019/12/reciclagem-reduzir-residuos.pdf>. Acesso em: 03 maio 2020.

Rev. Bras. Gest. Amb. Sustent., 2020, vol. 7, n. 17, p. 1637-1652. 
Scartezini, K. F. A. L. A efetividade das políticas públicas sustentáveis adotadas pelo Poder Judiciário Brasileiro à luz da Resolução CNJ no 201/2015. Brasília: Instituto Brasiliense de Direito Público, 2019. (Dissertação de mestrado).

Shrivastava, P.; Smith, M. S.; O’Brien, K.; Zsolnai, L. Transforming sustainability science to generate positive social and environmental change globally. Journals \& Books, v. 2, n. 4, p. 329-340, 2020.

Silva, D. R.; Santos, A. P. P.; Silva, L. B.; Glória, L. P. A gestão de resíduos sólidos vista a partir da produção científica. Revista CEREUS, v. 12, n. 1, p. 106-116, 2020. https://doi.org/10.18605/2175-7275

Silva, I. M. S.; Paraíso, L. A.; Pinto Jr., I. M. Análise crítica da Política Nacional de Resíduos Sólidos: principais pontos e aplicabilidade. Cadernos de Graduação, v. 4, n. 2, p. 37-48, 2017.

Silva, L. M. B.; Silva, J. P.; Borges, M. A. L. Do global ao contexto nacional: evolução da política ambiental brasileira. Revista Brasileira de Gestão Ambiental e Sustentabilidade, v. 6, n. 14, p. 593-608, 2019. https://doi.org/10.21438/rbgas.061401

Vansetto, C. C.; Ghisi, T. Resíduos sólidos e cooperativas de reciclagem: a Arquitetura como promotora social e ambiental. Labor e Engenho, v. 13, p. 1-13, 2019. https://doi.org/ 10.20396/labore.v13i0.8657063

Wanderley, L. A.; Araújo, C. C. Análise do setor de reciclagem no Estado da Bahia por mesorregiões entre 2007 e 2015. Revista de Desenvolvimento Econômico, v. 1, n. 39, p. 429-455, 2018. https://doi.org/10.21452/rde.v1i39.5444

Yukalang, N.; Clarke, B.; Ross, K. Barriers to effective municipal solid waste management in a rapidly urbanizing area in Thailand. Environmental Research and Public Health, v. 14, n. 9, 2017. https://doi.org/10.3390/ijerph14091013

Informação da Licença: Este é um artigo Open Access distribuído sob os termos da Licença Creative Commons Attribution, que permite uso irrestrito, distribuição e reprodução em qualquer meio, desde que a obra original seja devidamente citada. 